\title{
Innovative Way for Lay-up of Conical Shaped Sandwich Composite Component with Sharp Corner Radius
}

\author{
Farendra Singh Chouhan
}

\begin{abstract}
A new lay-up process has been invented, which involves a layer being made from three special shape prepreg. The first piece is butterfly shaped and remaining two pieces shaped trapezoid, with radius on smaller edge. Joining of all three pieces is butt-joint type. The subsequent layers are also in pieces of similar shapes with varying sizes. The lay-up of subsequent layers is carried out at an angle of rotation with respect to adjacent layer in clockwise direction. The component manufactured has no flaws and defects. This lay-up process reduces the wastage of raw material and also reduces the manufacturing cycle time.
\end{abstract}

Index Terms-Composite, lay-up, manufacturing, prepreg, interlaminar, flat wise tensile strength.

\section{INTRODUCTION}

Composite materials have emerged as the material of choice for reducing weight, cost and increasing the performance of military aircraft, general aviation aircraft, transport aircraft, Unmanned Aerial Vehicles and space launch vehicles. Major advancements have been made in design, fabrication and analysis of large complex aerospace structure. The use of composites can achieve weight reduction varying from $10 \%$ to $50 \%$ along with a cost reduction of $10 \%$ to $20 \%$ with equal performance when compared with components made of conventional metallic material [1]. A reduction of $1 \mathrm{Kg}$ mass leads to the reduction of fuel consumption of around 120 litres per year [1]. Composite material based applications have grown rapidly in the aircraft industry. The percentage of structural weight made from composite materials has grown from less than $1 \%$ to more than $50 \%$ over the past four decades [2]. Complex products involving many different types of parts produced in small lots/sub-assemblies are required in the aircraft industry. Hence, various molds, dies, tools and jigs-fixtures are required for manufacturing of relatively small number of sheet metal and composite parts. Composite parts and co-cured assemblies are unique as plies are placed one above the other to build a laminate. The placement of plies allows for structure to be precisely tailored, but have the possibility of individual plies being distorted within a laminate. In many cases these ply distortions may not be visible after the cure process. This makes the manufacturing development process very important. Internal fabrication anomalies must be

Manuscript received July 15, 2014; revised December 22, 2104. This work was supported by Hindustan Aeronautics Limited, Transport Aircraft Division, Kanpur, India.

Farendra Singh Chouhan is with Hindustan Aeronautics Limited, Transport Aircraft Division, Kanpur, India (e-mai: designstru.knp@hal-india.com). understood and well-characterized, to account for the design and analysis of the structure. The collection of laminated layers shaped onto the mold before curing is called a lay-up. Desired mechanical properties in composites are achieved by defined stacking sequence/lay-up. In a typical lay-up, the angular orientation of fibres in each layer/lamina is specified. The conventional method of lay-up to manufacture any composite part is to place all layers one by one (in single piece) at different angles to achieve the required thickness and strength.

\section{Methodology}

The dimensions of conical composite part are critical as per manufacturing point of view. The corner base radius is R", outer radius $\mathrm{R}^{\prime}$, thickness $\mathrm{T}$, Draft angle $\varnothing$ and maximum outer diameter of component is D (see Fig. 1). Following criticalities emerge from manufacturing point of view:

- $\mathrm{R}^{\prime \prime}+\mathrm{T}>\mathrm{R}^{\prime}$, (In present case, outer radius $\approx$ inner radius $\approx$ thickness)

- Wrinkles at the sharp corner radius

- Lay-up process

- Uniform thickness throughout the surface

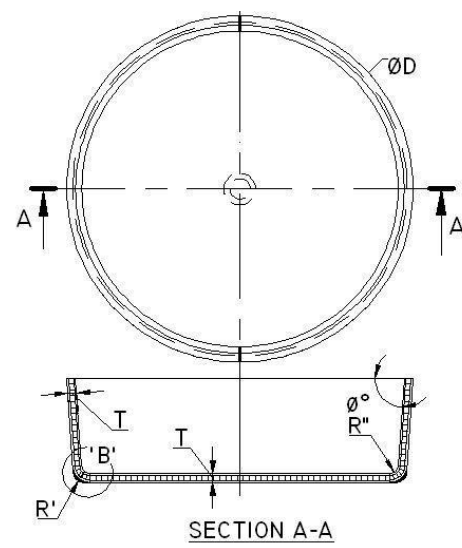

Fig. 1. Schematic view of component.

Therefore, conventional lay-up process is not feasible for conical shaped components with sharp corner radius because wrinkles appear at the sharp corner joints. Hence a need is felt to invent a non-conventional lay-up process to overcome such problems. Binding/splicing of hex core aramid honeycomb and ox-core aramid honeycomb is done through foaming core filler (see Fig. 2).

\section{A. Material Used}

All prepreg and aramid honeycomb raw materialsweresourced from $\mathrm{M} / \mathrm{s}$ Hexcel, France "unpublished" [3], "unpublished" [4]. The chemical, physical 
and mechanical property of aramid honeycomb is available on Hexcel website [5]. Following materialswere used to manufacture the component and specimens:

- HexWeb®HRH-10-3/16-3.0 (Hex core aramid Honeycomb)

- HexWeb®HRH-10/OX-3/16-3.0 aramidHoneycomb)

- HexPly®913/50\%/K285 (Kevlar prepreg)

- HexPly®913/37\%/120 (Glass prepreg)

- AF-3024 (Foaming Adhesive)

- EC-3500, Part A \& B (Core Filler)

- BJO-0930 (Micro-balloon Filler)

- LY 556 (Epoxy Resin)

- LN9169-8.4515.60 (Glass Cloth)

- HY 951 (Hardener)

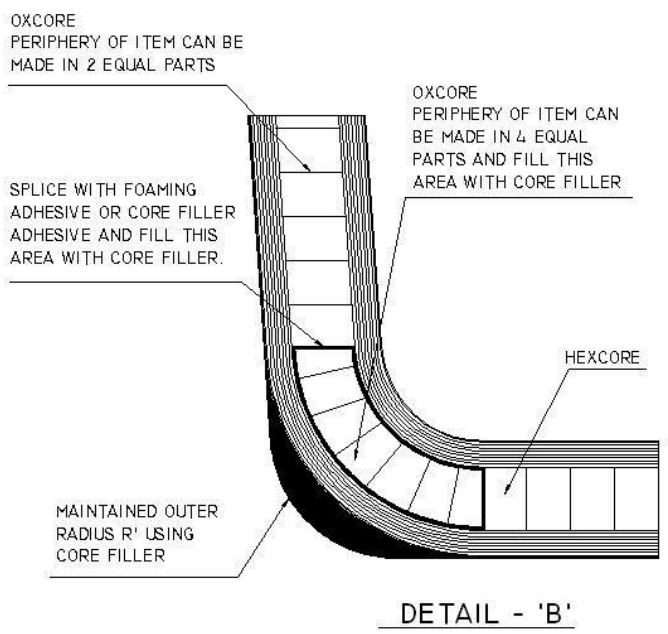

Fig. 2. Lay-up scheme.

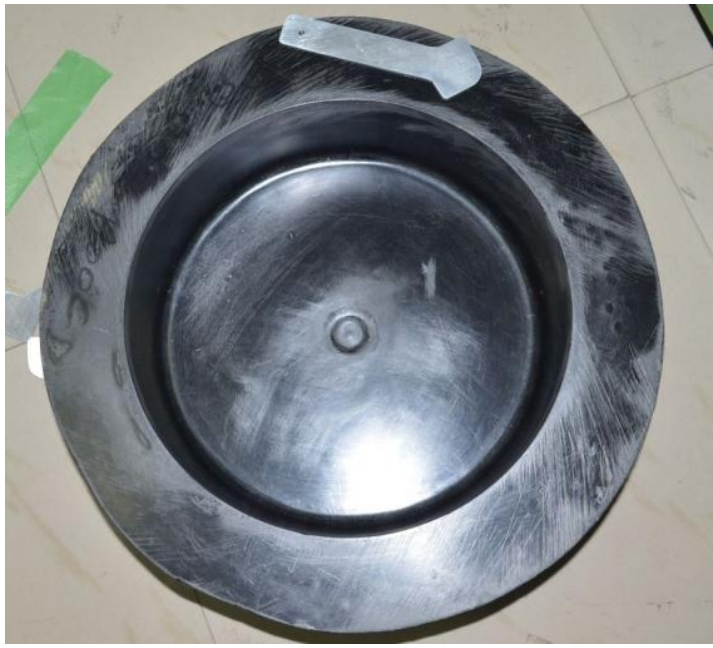

Fig. 3. Mold and metal tool

\section{B. Design and Development of Manufacturing Technology}

The first time development of the sharp corner radius sandwich composite component requires skill, experience and innovative thinking in lay-up technology and composite manufacturing. The following manufacturing technology was, therefore, invented to fabricate the component.

\section{Mold Construction}

It was requirement to make a high temperature resistance single piece mold. A female mold was developed using E-Glass fibre and epoxy resin with wet lay-up. It was developed with outer radius $\mathrm{R}^{\prime}$ at joining section of slant periphery and circular section (see Fig. 3). Another metal tool was developed with radius $\mathrm{R}^{\prime \prime}+\mathrm{T}$ (see Fig. 3). This metal tool helped in achieving the radius of $\mathrm{R}^{\prime \prime}+\mathrm{T}$.

\section{Development of Lay-up}

Outer radius was achieved by using core filler compound. After that, $\mathrm{R}^{\prime \prime}+\mathrm{T}$ radius was achieved by using metal tool (see Fig. 4).

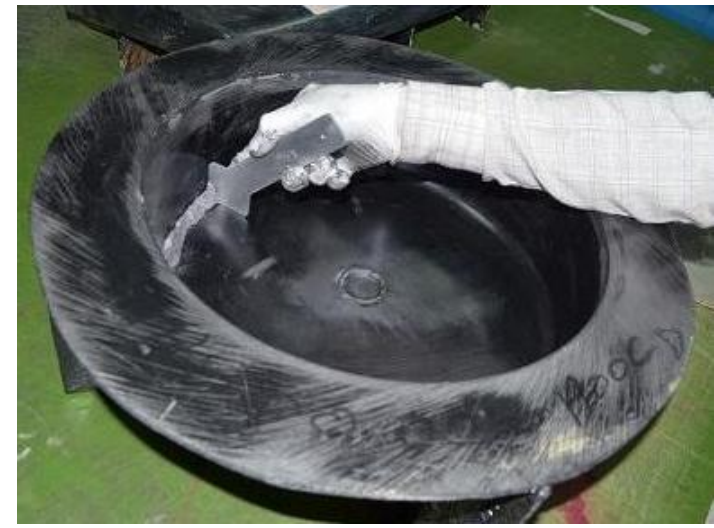

Fig. 4. Mold with achieving outer radius by using core filler.

During lay-up, the first layer of Glass prepreg was divided into three segments having special shapes. The first segment shape was butterfly with center portion diameter D1, second and third segment shape was trapezoid. The butterfly shape segment was aligned with $0^{0}$ reference line. All segments were laid-up with butt joint (see Fig. 5-Fig. 8).

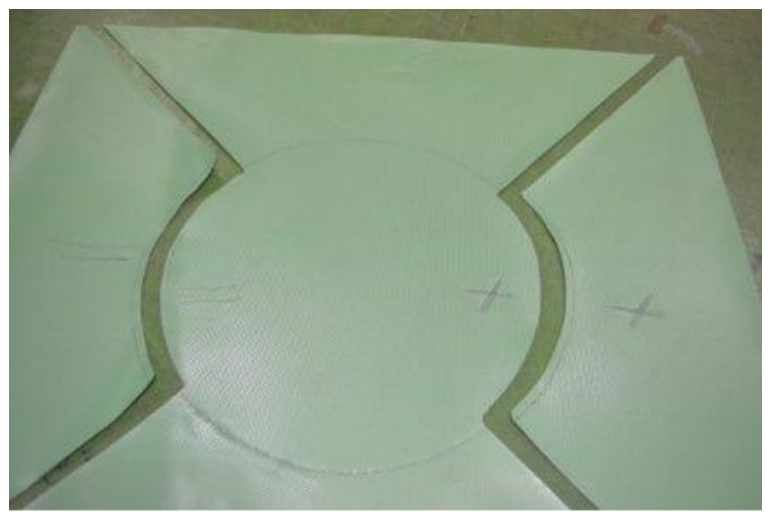

Fig. 5. Layer divided into three segments

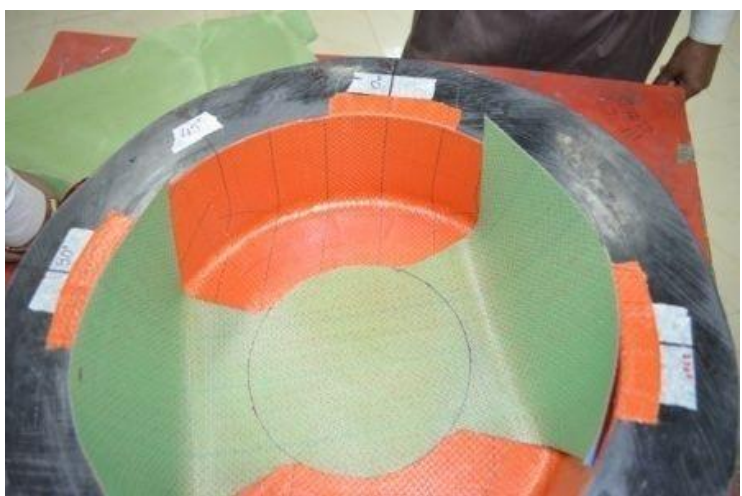

Fig. 6. Butterfly shape segment of layer position on mold.

If a layer of lay-up could not be manufactured from one single piece, the section of layer needed to overlap by $30 \mathrm{t}_{\mathrm{r}}$, 
where $t_{r}$ is patch thickness or $12-15 \mathrm{~mm}$ [6] or $15 \pm 2 \mathrm{~mm}$ to $25 \pm 5 \mathrm{~mm}$ depending upon the design requirement "unpublished" [7], "unpublished" [8].

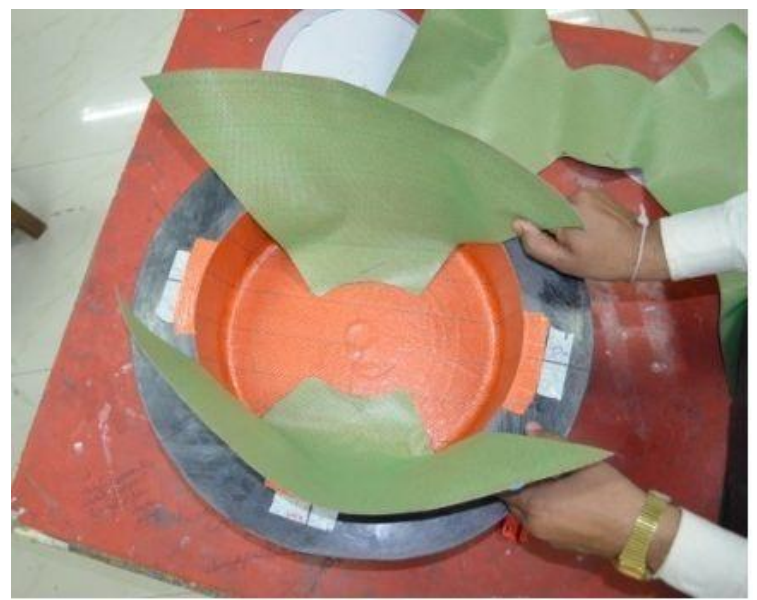

Fig. 7. Trapezoid shape segments of layer position on mold

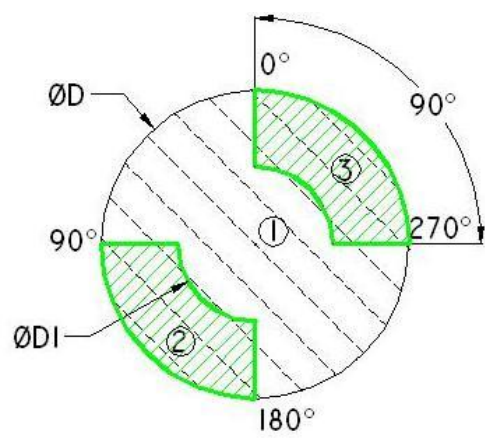

Fig. 8. Layer with butt joint.

The Second layer of Glass prepreg was also divided into three segments having special shape. The first segment shape was also butterfly, second and third segment shape was trapezoid. Diameter of circular portion of butterfly shape segment was increased by $30 \mathrm{~mm}$ with respect to previous layer. Butterfly shape segment was rotated at an angle of $10^{\circ}$ in clockwise direction with respect to $0^{\circ}$ reference line which fulfilled the design requirement and eliminated overlap requirement. All segments were laid-up with butt joint (see Fig. 9).

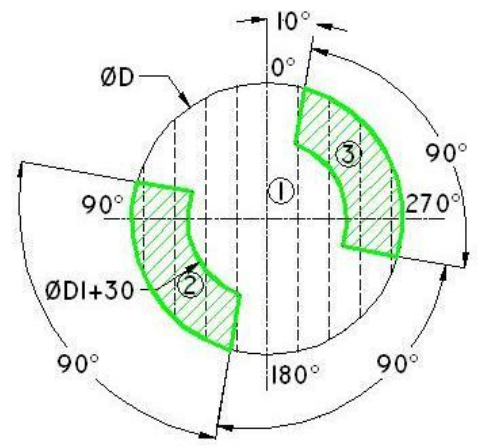

Fig. 9. Layer with $10^{\circ}$ clockwise rotation and $30 \mathrm{~mm}$ increase in diameter.

Further, next layer of Kevlar prepreg (third layer) was also divided into three segments having special shape. The first segment shape was butterfly, second and third segment shape was trapezoid. The diameter of circular portion of butterfly shape segment was further increased by $30 \mathrm{~mm}$ with respect to the previous layer. Butterfly shape segment was rotated at an angle of $10^{\circ}$ in clockwise direction with respect to adjacent layer which meant $20^{\circ}$ rotations in clockwise direction with respect to $0^{\circ}$ reference lines which fulfilled the design requirement and eliminated overlap requirement. All segments were laid-up with butt joint (see Fig. 10).

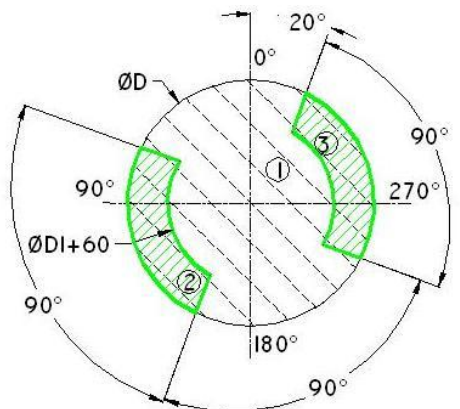

Fig. 10. Layer with $20^{\circ}$ clockwise rotation and $60 \mathrm{~mm}$ increase in diameter.

The further next layer of Kevlar prepreg (fourth layer) was also divided into three segments having special shape. The first segment shape was butterfly, second and third segments shape was trapezoid. The diameter of circular portion of butterfly shape segment was further increased with $30 \mathrm{~mm}$ with respect to previous layer. Butterfly shape segment was rotated at an angle of $10^{\circ}$ clockwise with respect to adjacent layer, which meant $30^{\circ}$ with respect to $0^{\circ}$ reference line and which fulfilled the design requirement and eliminated overlap requirement. All segments were laid-up with butt joint (see Fig. 11).

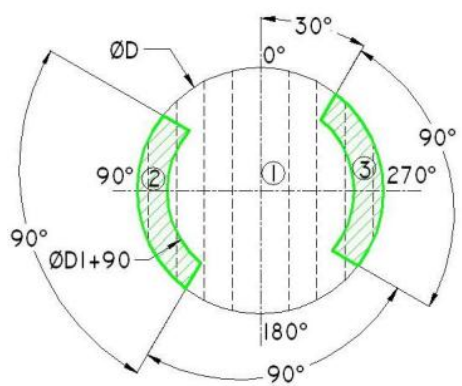

Fig. 11. Layer with $30^{\circ}$ clockwise rotation and $90 \mathrm{~mm}$ increase in diameter.

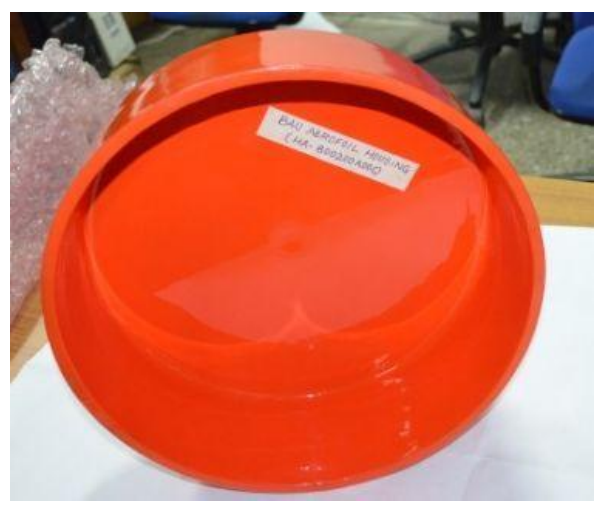

Fig. 12. Finished component.

The further next layer of Kevlar prepreg (fifth layer) was also divided into three segments having special shape. The first segment shape was butterfly, second and third segment shape was trapezoid. The diameter of circular portion of butterfly shape segment was reduced to diameter D1 which was equal to first layer diameter of Kevlar prepreg. But the 
rotation with respect to adjacent layer continued at an angle of $10^{\circ}$.

The whole process was repeated for all subsequent layers alternatively after every four layers. Vacuum bagging was carried out after every two layers to obtain a better surface finish and quality of the product. The sandwich component was made successfully to meet design requirement (see Fig. 12).

\section{CURING CYCLE}

The component and all specimens were cured as per standard cycle displayed in Fig. 13 "unpublished" [9]. The zone 1 heating rate was $1-2{ }^{\circ} \mathrm{C} /$ minute. First dwell (zone 2) was $75 \pm 5{ }^{\circ} \mathrm{C}$ for a period of $40+5$ minutes. The zone 3 heating rate also was $1-2{ }^{\circ} \mathrm{C} /$ minute. The second dwell (zone 4) was $135{ }^{\circ} \mathrm{C}$ for a period of $60+15$ minutes. The cooling rate (zone 5) was $<4{ }^{\circ} \mathrm{C} /$ minute. The pressure cycle started with 1.07 $\mathrm{MPa}$ (zone a) and it was constant approximate up to 20 minutes and then increased up to $2.1 \mathrm{MPa}$. The pressure cycle was kept constant till the end of curing cycle. The vacuum cycle was started with (zone I) $-0.989 \mathrm{MPa}$ and increased up to $-0.43 \mathrm{MPa}$. It was kept constant till end of the curing cycle.

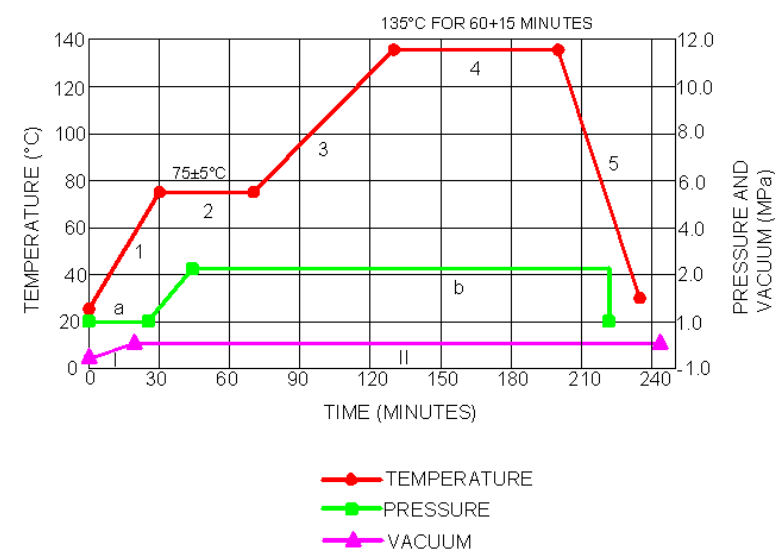

Fig. 13. Curing cycle.

\section{INSPECTION}

Following inspection was carried out on the finished component without surface protection:

1) External defects

The component was inspected for cracks, cut fibres, bubbles, resin rich area, resin starved area, process brake, pits and humps \& de-lamination as per MIL Standard [10].

2) X-ray test

X-ray test were carried out as per MIL Standard [10].

\section{Destructive Testing}

Following destructive tests have been carried out at coupon level:

\section{A. Flat Wise Tensile Test}

\section{1) Manufacturing of test specimen}

Six specimens were manufactured with $50 \mathrm{~mm}$ length and $50 \mathrm{~mm}$ width [11], [12], "unpublished" [13]. Two layers on each side of aramid honeycomb were laid-up and cured with component. Specimens were bonded with load introduction blocks by using Epoxy resin and Hardener and cured at room temperature $(23 \pm 3){ }^{\circ} \mathrm{C}$ under control relative humidity $(50 \pm 10)$ conditions for minimum 16 hours (see Fig. 14)[12], "unpublished" [13].

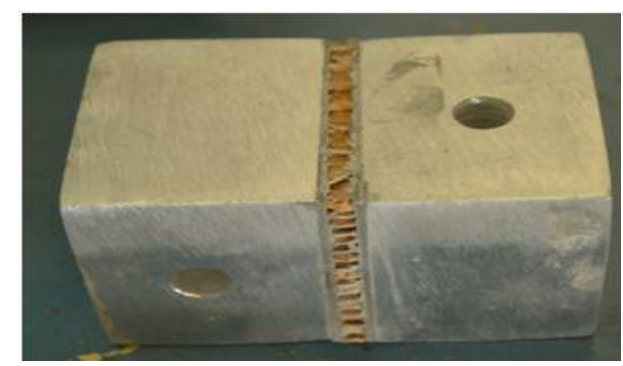

Fig. 14. Specimen bonded with load introduction blocks.

\section{2) Test conditions}

The edges length of the specimen were measured exactly upto $0.1 \mathrm{~mm}$ tolerance "unpublished" [13]. The test specimen was installed in computerised control Universal Testing Machine (UTM) using clamping device as displayed in Fig. 15.

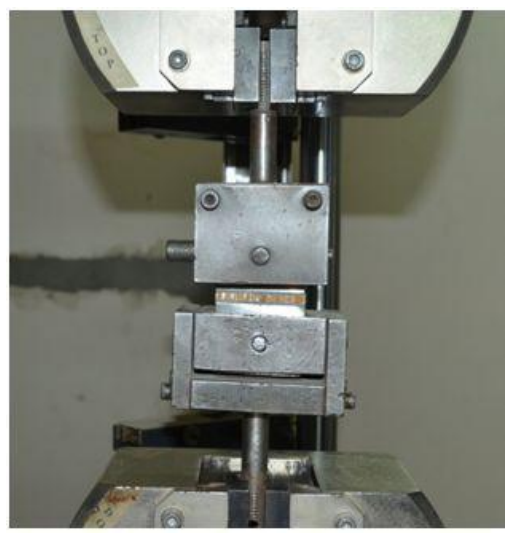

Fig. 15. Specimen installed in UTM using clamping device.

\section{3) Description of failure behaviour}

All the specimens were failed from the aramid honey core that met the design requirement as displayed in Fig. 16. [12], "unpublished" [13]. Hence there was no requirement to calculate the flat wise tensile strength of adhesive prepreg.

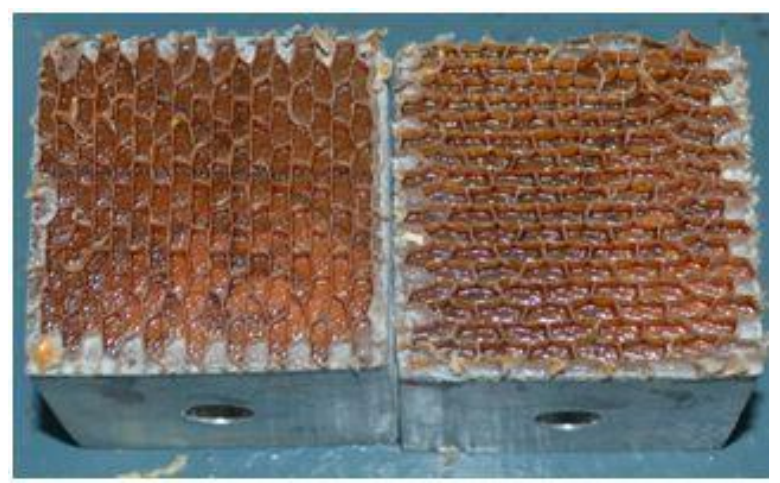

Fig. 16. Honeycomb core failure.

\section{B. Interlaminar Shear Strength Test}

\section{1) Manufacturing of test specimens}

Six test specimens were manufactured "unpublished" [13]. The specimen dimensions were as $20 \pm 1 \mathrm{~mm} \times 10 \pm 0.2 \mathrm{~mm} \times$ 
$2 \pm 0.2 \mathrm{~mm}$ "unpublished" [13], "unpublished" [14]. The manufactured specimens are displayed in Fig.17. Each specimen was manufactured with 8 layers of Kevlar prepreg. The stacking sequence of all specimens was[0/90/0/90]s. The measured dimensions for all six specimens were as displayed in Table I.

TABLEI: MEASURED DIMENSIONS OF SPECIMENS

\begin{tabular}{|l|l|l|}
\hline $\begin{array}{l}\text { Specimen } \\
\text { No. }\end{array}$ & $\begin{array}{l}\text { Width of the } \\
\text { specimen (a) in } \\
\mathrm{mm}\end{array}$ & $\begin{array}{l}\text { Thickness of the } \\
\text { specimen(b) in } \mathrm{mm}\end{array}$ \\
\hline 1 & 10.06 & 2.13 \\
\hline 2 & 10.03 & 2.06 \\
\hline 3 & 10.04 & 1.89 \\
\hline 4 & 10.06 & 2.04 \\
\hline 5 & 10.08 & 2.13 \\
\hline 6 & 10.04 & 1.94 \\
\hline
\end{tabular}

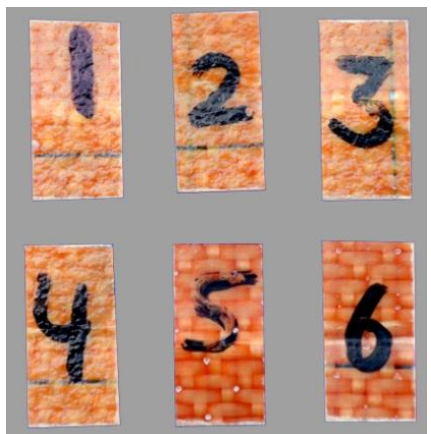

Fig. 17. Manufactured specimens.

\section{2) Test conditions}

All specimens were tested for a short beam bending test device (see Fig. 18.) in the longitudinal direction of the specimen. The machine speed was $1 \mathrm{~mm} / \mathrm{min}$ "unpublished" [13], [15].

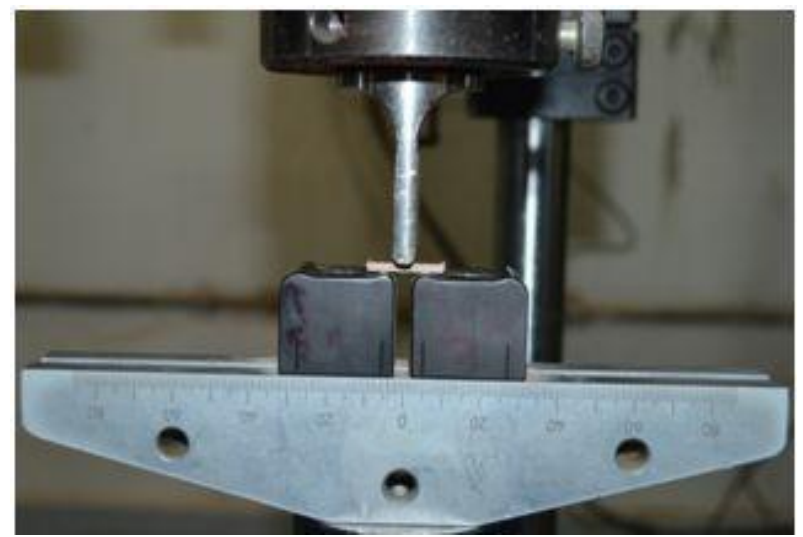

Fig. 18. Specimen installed in the UTM using clamping device.

3) Calculation of interlaminar shear strength

The Interlaminar Shear Strength was calculated in $0^{0}$ and $90^{\circ}$ direction as per "(1)", "unpublished" [13], "unpublished" [14], [15].

$$
\tau_{b B 0^{0}} \text { or } \tau_{b B 90^{0}}=0.75 * \frac{F}{a * b}
$$

where $\tau_{b B 0^{\circ}}$ or $\tau_{b B 90^{\circ}}$ is Interlaminar Shear Strength in $0^{\circ}$ and $90^{\circ}$ directions, respectively.

$F=$ applied force till fracture in $\mathrm{N}$

$a=$ width of the specimen in $\mathrm{mm}$

$b=$ thickness of the specimen in $\mathrm{mm}$

\section{RESULTS}

The test results at coupon level and components level were as given below:

- Flat-wise Tensile Test (FTT) at coupon level. All the test specimens failed from honeycomb core.

- X-Ray Test of the components for proper core splicing and to ensure no core damage. The X-ray of component met all the design criteria.

- Interlaminar Shear Strength (ILSS): Stress-strain diagrams for all six specimens are displayed in Fig. 19-Fig. 24. The obtained results of six specimens are displayed in Table II.

TABLEII: ILSS TEST RESULTS

\begin{tabular}{|l|l|l|}
\hline Specimen No. & Applied Force(N) & ILSS $\left(\mathrm{N} / \mathrm{mm}^{2}\right)$ \\
\hline 1 & 1173.40 & 41.070 \\
\hline 2 & 1124.70 & 40.825 \\
\hline 3 & 1002.60 & 39.627 \\
\hline 4 & 1114.30 & 40.725 \\
\hline 5 & 1138.30 & 39.762 \\
\hline 6 & 1044.90 & 40.234 \\
\hline
\end{tabular}

ILSS Test

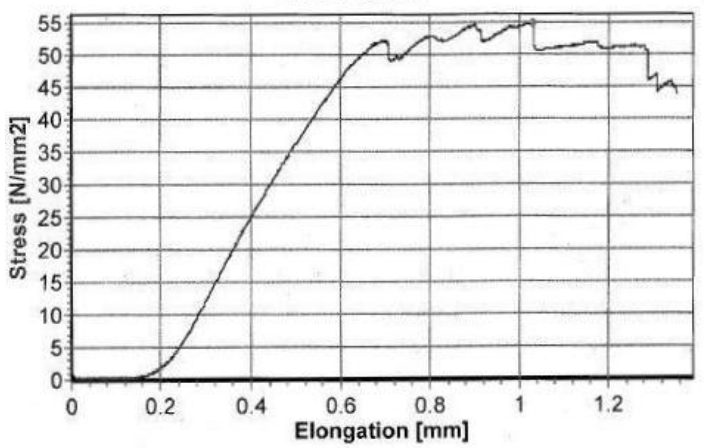

Fig. 19. Stress-Strain diagram for specimen 1.

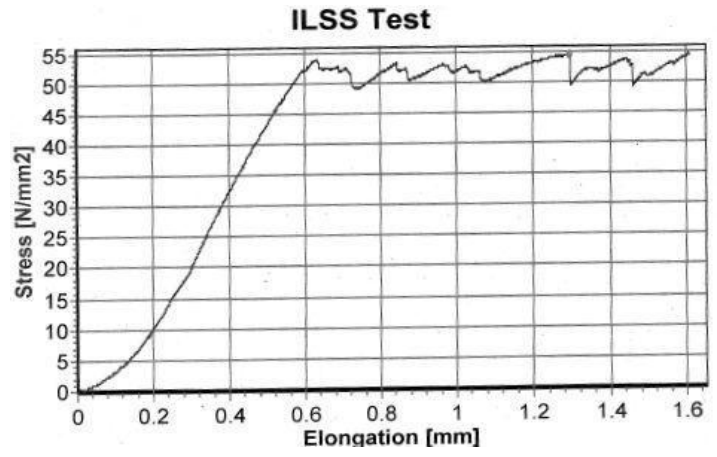

Fig. 20. Stress-Strain diagram for specimen 2.

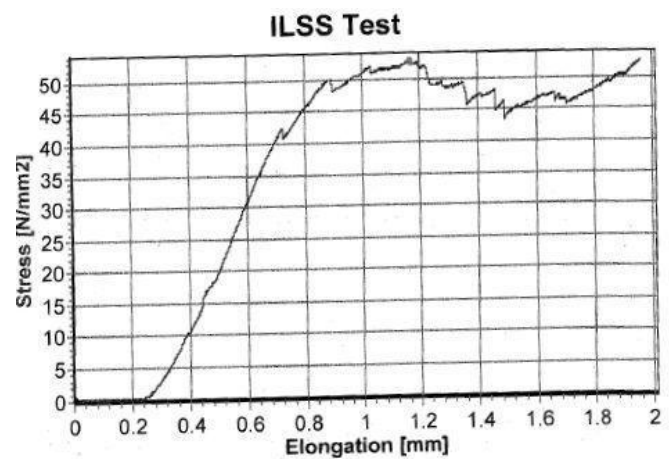

Fig. 21. Stress-Strain diagram for specimen 3. 


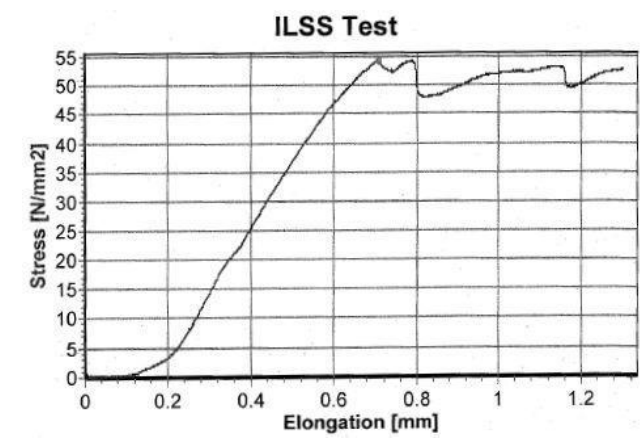

Fig. 22. Stress-Strain diagram for specimen 4.

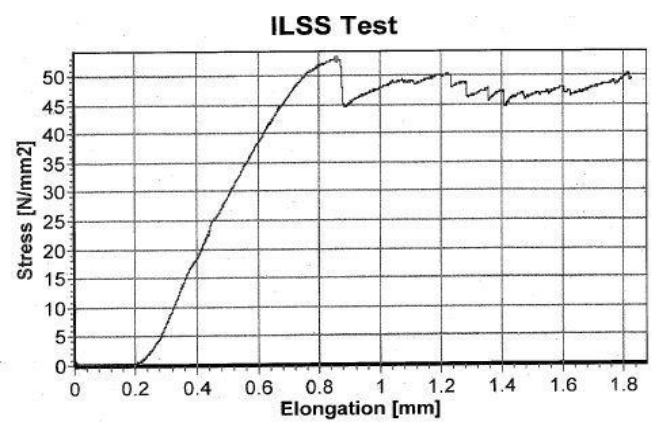

Fig. 23. Stress-Strain diagram for specimen 5.

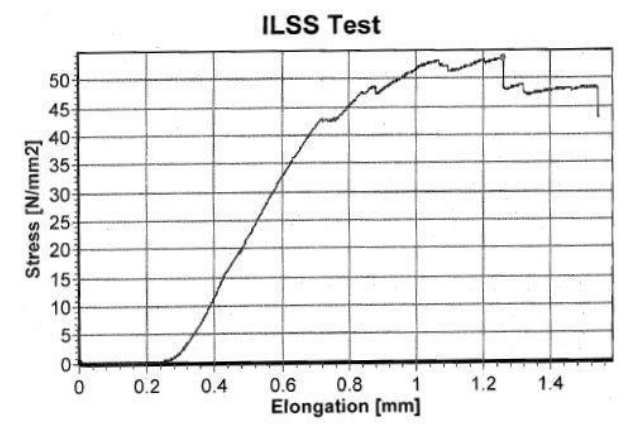

Fig. 24. Stress-Strain diagram for specimen 6.

The average value of ILSS Test Result was 40.3738 $\mathrm{N} / \mathrm{mm}^{2}$. The acceptable value of ILSS Test for Kevlar Prepreg is $37.92 \pm 2.76 \mathrm{~N} / \mathrm{mm}^{2}$ "unpublished" [13]. Therefore, the ILSS Test Results were acceptable.

\section{STATISTICS}

The average value, standard deviation, and coefficient of variation (in percent) were calculated refer to "(2),", “(3)," and “(4),"[12], [15].

$$
\begin{aligned}
\bar{X} & =\sum_{i=1}^{n} \frac{X_{i}}{n} \\
S_{n-1} & =\sqrt{\left(\frac{\sum_{i=1}^{n} X_{i}^{2}-n \bar{X}^{2}}{n-1}\right)} \\
C V & =100 * \frac{s_{n-1}}{\bar{X}}
\end{aligned}
$$

where:

$\bar{X}=$ Sample mean (average),

$S_{n-1}=$ Sample standard deviation,

$n=$ Number of specimen,

$X_{i}=$ Measured of derived property,
$C V=$ Coefficient of variation, in percent

$\bar{X}=40.3738 \mathrm{~N} / \mathrm{mm}^{2}$

$S_{n-1}=0.5938$

$C V=1.47 \%$

\section{CONCLUSIONS}

The present lay-up procedure used for manufacturing of sandwich composite components with sharp corner radius is unique because of the following reasons:

- The lay-up procedure eliminates any wrinkles during manufacturing of the component.

- The lay-up procedure reduces the wastage of raw material.

- Application of this lay-up process is simple. Therefore, lay-up procedure reduces the manufacturing cycle time.

- The lay-up procedure eliminates variation in thickness of joining areas of layers at bottom edge as well as at the periphery of the component.

- The first item is usually made as trial item for proving of process and composite tool. However, with this process, the first item itself was made with zero defects. The item was so conformal that it was used for the wind tunnel test. The wind tunnel test was successfully carried out by Indian Institute of Technology (Kanpur). The improved manufacturing process was adopted to achieve required finish and structural form of component.

- Similar lay-up process may be used for manufacturing of composite components with conical shapes of aircraft and other application also.

\section{ACKNOWLEDGMENT}

F. A. Author thanks Hindustan Aeronautics Limited for giving opportunity to work on such a challenging and innovative project. F. A. Author also thanks to Design Department, Aero Tooling Department and Composite Manufacturing Shop for giving all type of support. F.A. Author also thanks to Gp. Capt. (Retd.) V. S. Chauhan, Additional General Manager (Design), Shri K. G. Vadiraj, Deputy General Manager (Design), Shri Sanjeev Madhav Paniker, Senior Manager (Design), Sandip Kumar, Manager (Design), Umesh Kumar Verma, Engr (Design) and all my colleagues for providing me all type of support.

\section{REFERENCES}

[1] D. Gay, S. V. Hoa, and S. W. Tsai, Composite Materials Design and Applications, $4^{\text {th }}$ ed. CRC Press LLC, Boca Raton Florida 2003, ch.7, pp. 1-4.

[2] D. R. Tenney, J. G. Davis, N. J. Johnston, R. Byron, and J. F. McGuire. (May 2011). Structural Framework for Flight: NASA's Role in Development of Advanced Composite Materials for Aircraft and Space Structures. NASA/CR-2011-217076. [Online]. ch. 1. p. 1. Available:

http://ntrs.nasa.gov/archive/nasa/casi.ntrs.nasa.gov/20110012179.pdf

[3] Statement of Conformity According to Standard NF L 00-015CofHexPly®913/50\%/K285/HAL/1200mm, Certificate No. 303370 (1/1) December 2011.M/s Hexcel Composite, ZI 1A Plaine BP27 Dagneux, 01121 Montluel, Cedex France.

[4] Statement of Conformity According to Standard NF L 00-015Cof HexPly®913/50\%/120/HAL/1270mm, Certificate No. 241933(1/2) October 2009. M/s Hexcel Composite, ZI 1A Plaine BP27 Dagneux, 01121 Montluel, Cedex France. 
[5] Hexcel Composite. (August 2013). HexWeb®HRH-10®, Aramid Fiber/Phenolic Resin Honeycomb, product data. [Online]. Available: http://www.hexcel.com/Resources/Datasheets/Honeycomb-Data-Shee ts/HRH_10_us.pdf

[6] C. Soutis and F. Z. Hu, "Design and performance of bonded patch repairs of composite structures," Proc Instn Mech Engrs, vol. 211, part G, pp. 263-271, May 1997.

[7] Dornier 228 Structural Repair Manual, re.9, Hindustan Aeronautics Limited, India, February 2007, ch. 51-72-40, p.210.

[8] Unmanned Air Vehicle (UAV) Structure Repair, re.1, Hindustan Aeronautics Limited, India, December 2003, ch. 7, pp. 101-156

[9] Cure Cycle for Parts with Al face Sheets, Composite Face Sheets, FM73 and Low Density Nomex Core $\left(32 \mathrm{Kg} / \mathrm{m}^{3}\right.$ and $\left.40 \mathrm{Kg} / \mathrm{m}^{3}\right)$ Glass Reinforcements, HAL Standard SK/ALH/COMP/041, appendix 'D'. October 1995.

[10] Adhesive Bonded Metal Faced Sandwich Structures, Acceptance Criteria Military Specification, MIL-A-83376A (USAF) June 1978.

[11] Composite Materials Handbook, Polymer Matrix Composites Guidelines for Characterisation of Structural Materials, vol. 1, MIL-HDBK-17-1F, June 2002.

[12] Standard Test Method for Tensile Strength of Flat Sandwich Constructions in Flatwise Plane, ASTM Standards, C297/C297M-04, reapproved 2010

[13] Design Standard for Preimpregnated Lay-ups of Fibre-Fabric (GFRP, CFRP, and SFRP) with Epoxy Matrix of Dornier -228 Aircraft, DON 128 Part 1, February 1990.

[14] Inter Laminar Shear Strength (ILSS) or Short Beam Strength, HAL
Standard CMD/QAP (ALH)/024, August 2012.

[15] Standard Test Method for Short-Beam Strength of Polymer Matrix Composite Materials and their Laminates, ASTM Standard D2344/D2344M-00.

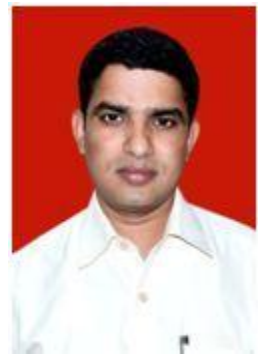

Farendra Singh Chouhan was born on May 1 , 1980. His areas of experience include design and development of repair schemes for repair of metallic and composite aircraft structure; design and development of aircraft structure by using Unigraphics software; also, design and development of repair scheme for repair of metallic and composite unmanned aerial vehicle (UAV); stress analysis and weight and centre of gravity report of aircraft airframe using Nastran/Patran software; development of supplement maintenance manual; supplement IPC etc for DO-228 and HS-748 aircraft; obtaining approval of structural modification for integration of different types' sensors, upgraded system, new system and surveillance system on DO-228 and HS-748 aircraft to meet the customer requirements from Centre for Military Airworthiness and Certification (CEMILAC) and Regional Centre for Military Airworthiness (RCMA). 